\title{
Animação sociocultural gerontológica com idosos frequentadores de centros de dia na região interior de Portugal
}

\author{
Sociocultural and gerontology animation promoter satisfaction with the life of elderly \\ regulars of day centers in the interior region of Portugal
}

\section{Ernesto Candeias Martins *}

\section{Resumo:}

Buscou-se abordar a animação sociocultural como promotora da satisfação e qualidade de vida no processo de envelhecimento de 68 idosos, de cinco centros de dia rurais, na região de Castelo Branco (Portugal). Foi um estudo de metodologia qualitativa, longitudinal, descritivo, analítico e interpretativo, no ano de 2015. Nortearam-nos os seguintes objetivos: promover o nível de satisfação com atividades culturais; desenvolver relações de convivência e autoestima; melhorar o clima social. Foi utilizado como técnicas de recolha de dados as entrevistas e observações aos idosos, responsáveis e técnicos, para além da análise às variáveis sociodemográficas de caraterização dos sujeitos intervenientes. Aplicou-se aos idosos um programa de atividades de animação sociocultural para melhorar o estado de ânimo, as relações, a convivência e qualidade de vida. Compreendeu-se a realidade social analisando as necessidades e exigências dos idosos e promoveu-se a sua participação nas atividades. O programa foi autoavaliado pelos idosos e técnicas responsáveis dos centros. Os resultados demonstraram o que os estudos confirmam: a qualidade de vida aumenta à medida que os idosos realizam tarefas e atividades socioculturais periódicas de que gostam e são protagonistas. Houve uma melhoria na autoestima, na satisfação com a vida e no clima social e institucional, através da animação cultural..

Palavras Chave: Gerontologia. Animação sociocultural. Idoso. Satisfação de vida. Centro de dia.

\begin{abstract}
:
We address the sociocultural animation as a promoter of the satisfaction and quality of life in the aging process of 68 elderly, five day centers, in the region of Castelo Branco (Portugal). It was a qualitative methodology, longitudinal study, descriptive, analytical and interpretive, in the year 2015. Guided us the following objectives: to promote the level of satisfaction with cultural activities; develop relationships and self-esteem; improve the social climate. We used as data collection techniques interviews and observations to the elderly, and technicians, in addition to the sociodemographic variables analysis of characterization of the subjects involved. We applied to the elderly a program of socio-cultural animation activities to improve mood, relationships, living and quality of life. We understand the social reality by analyzing the needs and requirements of the elderly and promote your participation in the activities. The program was evaluation by the elderly and technical responsible of centers. The results demonstrated that the studies confirm: the quality of life increases as the elderly perform periodic tasks and socio-cultural activities they like and are protagonists. There was an improvement in self-esteem, satisfaction with life and the social and institutional climate, through cultural animation.
\end{abstract}

Keywords: Gerontology. Sociocultural animation. Elderly. Life satisfaction. Day center.

\footnotetext{
* Doutor e mestre em Ciências da Educação. Docente no Instituto Politécnico de Castelo Branco/Escola Superior de Educação/Portugal. E-mail: ernesto@ipcb.pt
} 


\section{Introdução}

O envelhecimento demográfico tem-se acentuado na sociedade, assim como, modificações de comportamentos que repercutem-se, impreterivelmente nas estruturas populacionais de forma irreversível. De fato, o envelhecimento nos seus âmbitos biopsicossociais é um fenómeno de dimensão ínfima tendencialmente durável, irrecuperável e com efeitos em todas as sociedades (QUARESMA, 2004). Segundo dados da Organização Mundial da Saúde a esperança de vida mundial era, em 2000, de 66 anos de idade, passando em 2015 para 73 anos. Quanto à Portugal, o número de idosos e jovens traduziu-se, em 2010, num índice de envelhecimento de 118 idosos por cada 100 jovens, enquanto o índice de dependência (cuidados continuados) apresentava uma taxa de 26, 3, muito elevada na União Europeia. Entre 2020 a 2025 o número de idosos pode atingir cerca dos $18 \%$ da população, enquanto a população jovem rondará os 16\% (NAZARETH, 2009). Os próprios rendimentos (pensão de reforma, velhice ou sobrevivência) destes coletivos são escassos havendo $84 \%$ de pensionistas da Segurança Social com uma pensão mensal inferior a 500 euros e só 6\% com pensão superior a mil euros. Em 2009 havia uma taxa de risco de pobreza de $21 \%$, com tendência a aumentar à medida que vai avançando na idade.

Neste sentido as investigações sobre os aspetos (positivos) do envelhecer e da velhice adquiriram grande relevância, alterando as visões tradicionais que concebiam este ciclo de vida como declive e perda generalizada (PÉREZ BLASCO, 2013). A explicação das várias teorias sobre a velhice e os conceitos de envelhecimento satisfatório, com êxito e bem-sucedido insistem na capacidade dos idosos manterem a sua autonomia e em seguir implicados com a vida, experimentando novos ganhos. É verdade que as mudanças econômicas e sociais têm transformado as relações familiares e sociais e, hoje em dia, muitas das funções anteriormente desempenhadas pela família, por exemplo o cuidado e a atenção aos idosos é atualmente, uma função que cabe ao Estado ou ao setor privado, o que provocou o aumento do número de instituições de acolhimento (valências, equipamentos) (CARDÃO, 2009).

Estas instituições devem, não apenas promover ou satisfazer a função de bemestar, mas, também, que Ihes ofereçam mais teto, comida e assistência médico-sanitária, e momentos de ocupação; se querem que essas pessoas idosas continuem a fazer parte da sociedade, como agentes ativos. A generatividade (teoria do desenvolvimento de Erikson) destaca esta capacidade do indivíduo de desenvolver e participar em atividades 
institucionais e na comunidade, de tal modo que a generatividade implica em juntar o desenvolvimento pessoal com o social (ERIKSON, 2000). Neste sentido a animação sociocultural favorece à participação dos idosos e contribui para a sua cidadania ativa.

Situações como a solidão - individual ou social- o viver sozinho, sem vizinhos por perto, a falta de rendimentos, a inatividade no domicílio e nas instituições constituem fatores de risco para os idosos, em termos de necessidade acrescida à dos serviços de saúde, assistência e de bem-estar (ARAÚJO; CARVALHO, 2004). Perante estes dados, pensa-se que os idosos no futuro terão características distintas das atuais gerações, seja ao nível da instrução, nas condições de vida e de habitação, no acesso aos cuidados de saúde, nos diferentes valores e preferências, maior capacidade de participação e disponibilidade de recursos sociais.

O estudo abrangeu uma amostra de idosos $(n=68)$ de cinco centros de dia rurais (E1, E2, LO, LA, PR) que localizam-se num raio de 15 a $30 \mathrm{~km}$ da cidade de Castelo Branco, num total de 25 centros existentes. Os sujeitos desta amostra representativa estão aposentados, são maiores de 65 anos (média=80 anos, a mais velha tem 96 anos), frequentam diariamente os centros e são autônomos ou com uma dependência leve (critério de seleção). O problema que norteou esta investigação de metodologia qualitativa (descritiva, analítica e interpretativa), com aplicação prática em um programa de intervenção em animação sociocultural (PIAS), de índole investigação-ação e/ou participativa, foi: Será que um programa de intervenção em animação sociocultural aplicado aos 68 idosos de cinco centros de dia do concelho de Castelo Branco, melhora a satisfação, o estado de ânimo, às relações sociais e de convivência e, consequentemente, à qualidade de vida desses idosos?

Falou-se de centros de dia que são instituições/valências que os idosos frequentam para conviver, realizar atividades, partilhar ações e tomar as refeições principais. Ou seja, são instituições destinadas aos idosos que precisem de determinados serviços, dando prioridade às pessoas a partir dos 65 anos. São equipamentos que funcionam durante o dia e que prestam serviços sociais, culturais, recreativos, educativos, etc. mantendo essas pessoas no seu meio social e familiar. Atende-se às suas necessidades, estabilizam ou atrasam as consequências do envelhecimento, prestam apoio psicológico e social, promovem relações pessoais e intergeracionais, permitindo ao idoso continuar a viver na sua casa, evitando ou adiando o internamento em lares residenciais e, ainda prevenindo às situações de dependência. Por isso, os principais objetivos deste tipo de estruturas de apoio comunitário 
são: (i) recuperar ou manter ao máximo o grau de autonomia individual que permitam as potencialidades do individuo; (ii) prevenir o incremento da dependência através da realização de intervenções reabilitadoras; (iii) ser um meio facilitador do desenvolvimento de relações e atividades sociais gratificantes para o sujeito; iv) retardar as institucionalizações precoces e indesejadas; (v) promover à permanência do indivíduo no seu meio; (vi) proporcionar a realização de atividades básicas da vida quotidiana fornecendo apoio ao adulto idoso, assim como aos elementos pertencentes ao seu núcleo familiar; e por último, (vii) melhorar e manter o nível de saúde aos utilizadores através do controlo e prevenção de doenças. De um modo geral, os centros de dia favorecem às condições de vida das pessoas idosas dando-lhes dignidade e contribuindo para a manutenção e continuidade do seu modo de vida de autonomia.

Intentou-se compreender a realidade social de cada centro de dia em estudo, analisando as necessidades e exigências dos seus idosos e promovendo a sua participação através de um Plano de Intervenção Animação Sociocultural (PIAS), de modo a valorizar à intervenção da animação gerontológica na satisfação e qualidade de vida. Os objetivos do PIAS foram os seguintes: desenvolver a independência da pessoa do idoso na realização de atividades; contribuir para o bem-estar físico e psicológico nos idosos; criar momentos de aprendizagem e realização pessoal e social; promover os interesses e motivações dos idosos com atividades diversas nos vários âmbitos da animação (expressões, artística/lúdica, plástica, físico-motora, cultural, cognitiva, socias); adquirir novos conhecimentos e/ou aprendizagens através das atividades; prevenir a desorientação espaço-temporal mantendo um ritmo de execução das atividades de acordo com as suas capacidades e motivações diárias; desenvolver a confiança, a autoestima e a participação. Em termos de áreas de animação foi integrado: Animação físico-motora e sensorial; Animação artística (expressão plástica, lúdica e trabalhos manuais); Animação cognitiva; Animação para o desenvolvimento pessoal e social; -Animação cultural e social. Todas as atividades propostas visaram à autonomia e a qualidade de vida nos idosos (níveis de satisfação).

Os resultados demonstraram o que teoricamente afirmam as investigações: a qualidade de vida dos idosos desses centros aumenta à medida que realizam tarefas e atividades socioculturais periódicas. Em geral, a valorização dos idosos, responsáveis e técnicos confirmam: melhoria na autoestima e satisfação com a vida dos idosos ao realizarem atividades; expressam uma maior realização com o material produzido nas 
atividades; promovem um melhor clima social (amizades, relações, convivência), através da animação, e um autoconhecimento dos outros.

\section{Metodologia do Estudo}

A presente investigação, realizada em 2015, está elencada no Projeto Gerontológico (parceria Instituto Politécnico de Castelo Branco e Câmara Municipal com envolvimento de alunos de Mestrado Gerontologia Social), tendo-nos permitido conhecer a realidade dos idosos em centros de dia na região (problemas, motivações, interesses) e incrementou-nos a aquisição de conhecimentos fundamentais sobre velhice. Utilizou-se a metodologia qualitativa (paradigma interpretativo), de índole participativa, ativa e investigação-ação, proporcionando dinâmicas de grupo-orientadas à realização de atividades, associada aos interesses dos próprios idosos.

A parte da metodologia quantitativa destinou-se à análise das variáveis sociodemográficas dos sujeitos das amostras. Fez-se a opção por técnicas de recolha de dados à observação participante, observação documental (institucional, individual), entrevistas semiestruturadas na fase Pré-Programa de Intervenção Animação Sociocultural PIAS (13 questões) e na fase Pós-PIAS de avaliação (8 questões), aos idosos ( $n=68$ ), aos responsáveis diretivos $(n R=5)$ e diretoras técnicas $(n T=5)$. Com os registos observacionais (notas de campo) e as informações diagnósticas caraterizou-se os sujeitos e programou-se o PIAS (20 sessões em cada centro), sendo aplicado no 1. semestre. Após a recolha dos dados submeteu-se as entrevistas à análise de conteúdo. Os dados, com as notas de campo e registos observacionais, foram submetidos à triangulação. Previamente à aplicação daquelas técnicas, foram realizados contactos informais (intenções do estudo) e formais, cumprindo os requisitos legais e éticos (anonimato, confidencialidade, privacidade) de uma investigação social: protocolo a cada instituição (autorização), termo de livre aceitação dos idosos, e dando a conhecer os objetivos do estudo a sua finalidade. No final do estudo as 5 instituições participaram na organização de uma Feira Intergeracional do Idoso (julho de 2015 no Louriçal do Campo), que envolveu também crianças/jovens do Agrupamento de Escolas, associações culturais e entidades locais. 


\section{Análise Interpretativa dos Dados}

Fez-se uma análise de conteúdo às entrevistas, através do sistema de codificação e categorização. Da análise aos segmentos de texto (parâmetros de evidências) passou-se à sua interpretação elaborando sínteses com os aspetos mais significativos (descritores, evidências). Esta análise concentrou-se nas frases e narrações dos sujeitos, guiando-nos por um critério holístico, no sentido de que o individuo é percebido e estudado na sua totalidade e representação social. A apresentação dos resultados produziu-se de acordo com a perspetiva narrativa ou linguística do afirmado (indicadores expressivos dos juízos contidos no discurso da frase). Ou seja, estabeleceu-se indicadores e procurou-se o seu sentido integrando-o na respetiva categoria/subcategoria (procedimento desconstruído, sincrónico e sucessivo).

\section{Entrevistas aos idosos}

A entrevista Pré-PIAS aos idosos tinha 13 questões abertas (pergunta 6 desdobravase em duas: 'como passa os seus tempos livres?' e que 'atividades costuma fazer?') e só as questões 8 e 10 eram de escala nominal (Sim/Não). As categorias/subcategorias estabelecidas foram as seguintes: Categoria Centro de Dia - 'Razões de escolha' (Q1), 'O que é mais importante no Centro' (Q 2), 'Importância local do centro' (Q 3), 'Serviços prestados' (Q4) e 'Relação exterior do Centro (família/comunidade) (Q 5); Categoria Recreação 'Tempos livres' (Q 6), 'Importância da ocupação dos tempos livres' (Q 7), 'Tipo de atividades em que participa' (Q 8), 'Decisão sobre as atividades' (Q 9), 'Sugestões' (Q 10) e 'Atividades Novas a promover' (Q 11); Categoria Bem-estar e Qualidade - 'Mudava algo no centro (Q 12) e 'Centro de dia amigo dos idosos' (Q 13). Da análise categorial destacaram os seguintes descritores/evidências:

*-A 'viuvez' e/ou 'Viver sozinho' e o estar perto de casa são os motivos que maioritariamente levam os idosos a frequentarem ao Centro. Não indicam a alimentação/comida e a higiene em primeiro lugar, quando em outras questões as referem. Em alguns centros responderam: 'Sabe...espero que consiga ter alguém até ao final, porque fiquei sozinho".

*_ O 'apoio', a 'alimentação/comida' e a 'companhia' ou 'comida/convívio' e 'roupa/higiene' são os serviços mais destacáveis nos idosos, os quais valorizam 
esta decisão repetindo: 'Olhe ainda bem que há estas casas para nos acolher senão era muito triste'.

*_ Os idosos valorizaram positivamente a relação 'Centro com o exterior' (comunidade local) designando-a de forma unânime de 'Muito boa', 'Muito importante'.

*- Os idosos designam de 'Muito boa' (90\%) os serviços prestados, destacando a alimentação, como um dos melhores serviços, seguido 'apoio assistencial e social' e higiene. Em LO indicam maioritariamente todos os serviços do centro, sem distinção. Em geral consideram: 'O centro é a nossa segunda casa. Há uma relação muito próxima'.

*- Maioritariamente os idosos valorizam a relação do Centro com a família de 'Muito Boa' (80\%), havendo uma harmonia dos responsáveis, técnicos e cuidadores com as famílias.

*- Os idosos têm poucas ou nenhumas atividades diárias nos centros de dia e quando as têm são em datas pontuais. Habituaram-se a ver TV, a rezar, a dormir, isolar-se, etc., exceto no Centro LO onde há um grupo de idosas que fazem renda e elaboram objetos diversos.

*- Todos os idosos dos centros consideram que gostam muito de ocuparem o seu tempo em atividades de interesse ou inovadoras (unanimidade -'Sim' gostam muito).

* - A participação em atividades do centro é escassa e pontual (Natal, Páscoa, Carnaval, Dia do Idoso, aniversários, etc.), cumprindo o seu Plano Anual/Trimestral. Esta falta de participação deve-se também a algumas limitações físico-motoras (E2) e/ou cognitivas (PR).

*-Em relação às sugestões e decisões de proporem atividades nos centros, cabe às técnicas decidirem os planos de atividades, comentando com os idosos as tarefas (novas) que querem fazer. Esta escassez de sugestões implica falta de motivação e diálogo com os idosos. Ao não serem estimulados acabam por perder algumas faculdades e não sabem o que dizer. A técnica de LO é a que promove mais atividades.

*-A maiorias dos idosos acostumaram-se a fazer poucas atividades e, por isso parecem-lhes bem a repetição de algumas. Os idosos de E1, E2 e LA propõem a música (animação social, musicoterapia), as expressões e a ginástica. 
*_ A maioria dos idosos não mudaria nada no centro, pois estão satisfeitos com os serviços. O seu nível de exigência é muito fraco, parecendo-lhes tudo bem e não se acham no direito de dizer seja o que for.

*- 'Centro Amigo do Idoso' tem, para eles o significado de 'apoio' e 'ajuda' prestada (serviços), por isso consideram-no 'amigo', porque 'ouvem' e preocupam-se pelos idosos.

Há um certo conformismo nos idosos na realização de atividades, porque não estão habituados a ter uma programação semanal/mensal. Valorizam a instituição neste ciclo de vida, as relações com a família e comunidade e a ação dos funcionários. A sua representação social sobre o centro é o de ajuda, apoio e 'ser amigo' deles. A proposta do PIAS pretendeu incrementar os níveis de satisfação e da qualidade de vida destas pessoas idosas.

\section{Análise das entrevistas aos responsáveis e diretoras técnicas}

Foram aplicadas as entrevistas semiestruturadas aos dirigentes (R-E1, R-E2, R-LA, RLO, R-PR) e às diretoras técnicas (T-E1, T-E2, T-LA, T-LO, T-PR). Destacam-se as seguintes variáveis de identificação em ambas amostras:

*-Responsáveis dirigentes: a maioria é do sexo feminino (75\%), excluindo E1 e LO (masculino=25\%); média de idades cerca de 56 anos, exceto em E1 e LA que ronda os 70 anos; todos casados (estado civil), exceto em LA (solteira); grau de habilitações literárias elevado (licenciados e mestrados), exceto em E1 (4.a classe); residem na mesma povoação, exceto LA; ocupam o cargo há mais de 4 anos, exceto E2 (20 anos) e LO (um ano).

*-Diretoras técnicas: são todas mulheres, licenciadas em Serviço Social e residentes em Castelo Branco. São duas solteiras (T-E2; T-PR), duas casadas (T-E1, T-LA) e uma divorciada (T-LO), com uma média de idade de 33 anos. Trabalham na instituição há mais de 3 anos e no regime de contrato temporário, deslocando-se 3 a 4 dias por semana.

A segunda parte das entrevistas continha 12 itens, sendo o primeiro destes itens relativo aos anos no cargo ou anos de serviço como responsável ou diretora técnica. Foram analisados os respetivos itens: 
-'Nível dos serviços prestados'. Todos os responsáveis se referem ao que a lei prevê nos serviços a prestar e a sua adequação às necessidades dos idosos, mas nem todos centros cumprem na totalidade essa missão. Nota-se que as pessoas que estão nestes cargos, já levam muito tempo e têm pouca inovação (medidas), exceto em R-LO.

-'Importância local do centro' - Atribuem uma grande importância à instituição, destacando o apoio às famílias e à empregabilidade local (R-LO), indo ao encontro das necessidades básicas dos idosos (apoios, serviços).

-'Objetivos do Centro' - Todos referem a qualidade, satisfação e o bem-estar como objetivos centrais, pois o centro constitui o grande suporte para a família e para os idosos.

-'Execução dos objetivos' - Todos mencionam que há uma adequação dos objetivos à missão e à valência da instituição, a qual se empenha em dar aos idosos uma boa qualidade de vida, garantindo as suas necessidades básicas do quotidiano.

-'Realização de atividades' -Todos tiveram uma noção clara da importância das atividade, mas na prática fazem poucas, já que as técnicas estão em contratos de 'par time'.

-'Animação socioculturais no centro' - Todos reconhecem que a animação é promotora de satisfação, terapia ocupacional e bem-estar. Consideram-na primordial para o bem-estar físico e psíquico dos idosos, uma vez que estes ganham autoestima e autonomia.

-Relação 'Centro - Família' - É 'Muito boa' (unanimidade). Esta tarefa não é fácil porque alguns familiares não se interessam pelos idosos, regularmente visitamnos aos domingos, mas não sabem o que fazem no centro. Notou-se que é muito difícil falar com determinados familiares.

-Articulação 'Centro - Comunidade' - Todos valorizam esta relação de 'Muito Boa', destacando as entidades locais (junta de freguesia, paróquia), exceto o R-E2 ('Boa').

-'O que mudaria no centro?' - Todos mudariam algo, por exemplo, novas instalações e melhores condições (R-E1), mais cuidadores/técnicos (R-LA; R-PR) ou uma valência de lar (R-LO). Alguns dirigentes contratariam mais funcionários (R-E1, R-LA, R-LO). 
-'Qualidade de vida no idoso' - Está relacionada com as necessidades básicas (biopsicossociais), bem-estar físico e psíquico (saúde) dos idosos ou o 'saber ouvilos' (assertividade e acuidade) (R-PR).

-'Centro amigo dos idosos' - As instituições destinam-se a preocupar-se e a compreender os idosos, satisfazendo-lhes as suas necessidades e dando-lhes qualidade de vida. Daí que o centro amigo é o que os ajuda e compreende.

Analisou-se as mesmas questões feitas às diretoras técnicas dos centros:

-'Nível dos serviços prestados'. Todas as técnicas referem à qualidade dos serviços, preferentemente os básicos do dia-a-dia (necessidades). Há coincidência com o discurso dos responsáveis na prestação e adequação às 'necessidades'.

-'Importância local do centro' - Devido ao envelhecimento demográfico os centros asseguram à qualidade de vida nos idosos, promovendo-lhes relações de proximidade (comunidade, família). Há coincidência com o discurso dos responsáveis.

-'Objetivos do Centro' - As técnicas são unânimes que os centros assegurem à satisfação das condições básicas, promove o bem-estar e a autoestima dos idosos. Há coincidência com o discurso dos responsáveis dos centros.

-'Execuções dos objetivos' - Todas as técnicas cumprem os objetivos relativos à missão institucional e às necessidades dos idosos. Reconhecem que se pode fazer 'algo mais'.

-'Realização de atividades' - As técnicas realizam atividades adequadas aos interesses e limitações dos idosos, mas são escassas. Reconhecem que eles necessitam de motivação e que as estratégias usadas não são as melhores. Escasseia-Ihes formação em animação.

-'Relações com a família'. Todas as técnicas confirmam a boa relação com a família, mas essas relações podem melhorar criando mais laços de amizade e confiança.

-'Animação sociocultural no centro' - As técnicas fazem uma definição clara de animação e da sua importância no bem-estar, no desenvolvimento pessoal e social, na criatividade, relações e participação, mas na prática não operacionalizam estas ideias. A representação social do seu discurso coincide com a dos responsáveis. 
-'Articulação Centro - Comunidade' - Há coincidência com o discurso dos responsáveis ao designarem por unanimidade de 'Muito Boa' essa relação.

-'O que mudaria no centro?' - Há coincidência com o discurso dos responsáveis ao desejarem mais recursos técnicos. Destaca-se T-LO e T-LA ao desejarem uma animadora.

-'Qualidades de vida no idoso' - As técnicas destacam o significado da 'qualidade de vida, coincidindo com alguns dos responsáveis, principalmente na relação com as necessidades básicas (biopsicossociais), bem-estar (saúde), aceitação e felicidade. Para elas a qualidade passa pelo apoio ao idoso, criando-Ihe satisfação.

-'Centro amigo dos idosos' - As técnicas atribuem este significado ao apoio e carinho (afetividade) aos idosos, à sua segurança e em mantê-los ocupados, ou seja, uma instituição que satisfaça as suas necessidades dá-lhes qualidade e felicidade/bem-estar emocional.

É notório que os discursos narrativos dos dirigentes e das técnicas coincidem na sua representação do discurso social coletivo, havendo uma preocupação pela satisfação das necessidades e promoção da qualidade de vida (ARAÚJO; CARVALHO, 2004). No âmbito da animação sociocultural todos os centros escasseiam dessas atividades, já que essas técnicas, formadas em Serviço Social, não têm um complemento formativo em animação (SILVA; MOINHOS, 2010). Isto vai ao encontro da importância que tem a animação nestas valências, da utilidade de um programa de animação, que inclua atividades diversificadas e adequadas.

\section{Programa de Intervenção Sociocultural aos Idosos}

As 20 sessões de animação, nos centros de dia, ocorreram uma ou duas vezes por semana e ao sábado. Previamente estabeleceu-se a duração das atividades, mas por vezes dependeu das destrezas de cada idoso. As sessões executaram-se de acordo com os objetivos, características dos idosos e do que gostariam de fazer (JACOB, 2007). Em todas as atividades realizadas houve apoio afetivo-emocional, indo ao encontro das suas problemáticas, desdramatizando situações causadas pela perda de capacidades e atuando estados de ânimo, de modo a permitir às pessoas portadoras de alguma limitação participarem, valorizando-se pessoal e socialmente (MARQUES, 2011, p. 2-6). Usufruíram plenamente dos seus direitos e sentiram-se cômodos ao executar as tarefas. Respeitou-se os ritmos, gostos, saberes, interesses e aprendizagens (significativas). As sessões mesmo 
planeadas previamente, nem sempre seguiram o plano, dadas as imprevisibilidades e o ritmo de cada idoso.

Normalmente, cada sessão estava dividida em duas partes: uma de manhã e outra à tarde, consoante a natureza das atividades, a disposição e gostos dos idosos. As atividades iniciais eram de animação físico-motora e sensorial (mobilidade, flexibilidade e agilidade), no sentido de levar os idosos a descontrair e a participar e, em seguida executavam-se as atividades de caráter cognitivo e cultural. De tarde, realizou-se atividades de expressão plástica, artística e lúdica. Durante o desenvolvimento das atividades apresenta-se os objetivos e o modo de fazer, com intuito de os motivar para se envolverem nas tarefas. Os recursos materiais de apoio foram previamente pedidos, garantindo-se a preparação das atividades, distribuídas por grupos. No final de cada atividade passou-se uma ficha de autoavaliação e no final fez-se 'focus groupe' - entrevista de discussão sobre o ocorrido.

A maioria dos idosos gostou e desfrutou da atividade física sensorial e motora: “É muito bom, as pernas e as costas pesavam, e passado algum tempo ficam aliviadas' (LA-9, LO-4). Esta atividade pretendia que os idosos relaxassem o corpo e a mente ao som de uma música adequada. Outra atividade que gostaram imenso foi a 'expressão plástica e lúdica', dobragem de revistas (dois modelos diferentes o simples e o duplo), para no final sair numa a vela e na outra um boneco: "Tem a certeza que é mesmo uma vela e um boneco? (E1-3), 'Não somos capazes!' (LA-1), 'Bem, já conseguimos dobrar' (E2-5), 'Não ficou parecido com uma vela nem um boneco?' (LO-10), mas todos conseguiam fazer (emoções positivas). Foram feitos marcadores de livros com vários materiais (feltro de várias cores, cola, desenhos alusivos ás épocas, pedaços de renda, cartolina de várias cores, fitas de cetim) e a "construção do jogo do galo", cujo objetivo era recordar como se jogava e depois construílo, para que eles conseguissem jogar. Tratou-se de uma atividade muito participada e de interesse comum.

Foram lidos (voz alta) alguns textos a pedido dos clientes (Ateliê de leitura) para que todos pudessem estimular a memória com essas leituras (expressões, frases) as quais eram muito bonitas, debateu-se o tema da família: "hoje em dia já não havia o conceito de família uma vez que as pessoas estão mais egoístas " (E1-4, LA-6, LO-7, PR-2). No final da atividade, os idosos tinham a liberdade de poder dialogar e dar sua cintribuição, partilhando a história e discutindo o significado das palavras na sua vida, nas relações e experiências. 
Todas as sessões decorreram no ambiente alegre, salvo alguns dias em que alguns idosos estavam com baixos estados de ânimo. Uma das dificuldades iniciais foi o fato dos idosos não desenvolverem a troca de opiniões, a comunicação entre eles, pois isolavam-se. Foram desenvolvidas capacidades de carater pessoal e social (GONZÁLEZ RODRíGUEZ; MUÑOZ MARRÓN, 2008). O animar passou a significar para eles uma capacidade de promoção da interação entre eles (convívio), potencializando a sua capacidade expressiva/comunicativa.

\section{Valorização do Programa de Intervenção de Animação Sociocultural}

Após a aplicação do PIAS solicitou-se aos idosos, responsáveis dirigentes e diretoras técnicas que efetuassem a sua avaliação, através de entrevista individual com 8 questões, sobre a execução do programa, o impacto que teve na vida da instituição e nos seus idosos.

\section{Satisfação nos idosos}

Uma vez que trabalhou-se mais as áreas das expressões plásticas, artísticas e culturais, houve o cuidado de saber se tinham realizado algumas atividades, mas a maioria tinham feito poucas, exceto em LO e LA. Daí o ajuste do programa às outras atividades de interesse nestas áreas da animação sociocultural. Algumas atividades demorarem muito mais tempo do que o esperado e, outras coincidiam com a proximidade de datas festivas, por exemplo, a Feira intergeracional, o dia dos Avós, dos Namorados, o Carnaval, festa religiosa local, dia do aniversário, etc., o que obrigou a integrá-las no nosso plano. Assistiu-se a uma grande progressão de centro para centro devido, em parte, à participação de algumas técnicas na estimulação cognitiva dos idosos (GONZÁLEZ RODRÍGUEZ; MUÑOZ MARRÓN, 2008). As fichas de autoavaliação foram passadas no final de cada módulo (áreas) do PIAS, sendo valorizadas, com a ajuda das notas de campo, observação participante e entrevista em grupo.

A autoavaliação foi analisada (fichas):

*- Em relação aos escores de pontuação (escala de Likert) de 'gostar da atividade realizada', a totalidade dos idosos manifestaram 'Muito' (intervalo 4). Ao ser passada a ficha no final da tarefa o gosto de realizá-la expressou um contentamento elevado de 'fazer' e 'ser capaz' nos idosos. 
*- Na opinião sobre a atividade ('divertida' ou 'aborrecida', na mesma escala) todos os idosos dos centros de dia disseram 'Muito divertida' (intervalo 5).

*- No 'aprender algo de novo' com a atividade realizada, os idosos manifestaram palavras conotadas com a dimensão emotiva e sentimental ('bonito', 'interessante', 'fácil', 'engraçado', 'faz bem à saúde', 'gostamos muito', foi coisas novas, etc.).

*- A maioria dos idosos disse que 'Não' (75\%) conhecia a atividade realizada.

*- Sobre qual das 'atividades que preferiram', a maioria dos idosos disseram 'Todas' (80\%), mas alguns destacaram mais a 'ginástica', seguido de atividades lúdicas e culturais. Em PR as opiniões foram mais dispersas, devido ao grupo de idosas muito ativas, que estão sempre interessadas em algo 'novo' (exigência).

*- Em relação ao 'Sentido da aprendizagem' (aprender a aprender) os idosos manifestaram as seguintes respostas: 'Aprendemos muito', 'foi interessante', 'aprendemos algo esquecido', 'convivemos em grupo'.

*- Na 'atividade que menos gostaram' não houve discurso negativo, pois a maioria dos idosos gostaram de todas, exceto algumas tarefas mais trabalhosas e de maior concentração.

Pode-se afirmar que as autoavaliações dos idosos foram muito positivas e motivadoras para a avaliação do PIAS, podendo sintetizar algumas ideias reflexivas:

? Alguns idosos não conseguirem fazer os trabalhos como eles queriam e estiveram para desistir de algumas atividades, dizendo: "Olhe o que me está a propor é muito difícil" (E1-6, E2-2, PR-9); "Se ficar ao meu lado farei tudo, senão, não vale a pena insistir" (E2-1);

? Nota-se que em alguns dos centros de dia os idosos não são estimulados, daí a recusa inicial em participarem nas atividades: 'eu já sou velha para quê fazer isto, não sei" (E1-9, LA-3, LO-7), muitas vezes não era o gostar da atividade, mas o fato de participar e entrar no desconhecido. Passado algum tempo proferiam: " $E$ assim que se faz", "afinal não é difícil" (E2-4) reforço) e experimentavam.

? Do ponto de vista físico-motor houve idosos que queriam participar nas atividades, mas as suas limitações físicas não favoreciam: "tenho as pernas que 
não ajudam nada" (E1-2), "doem-me as mãos e os dedos dos pés" (LO-6, PR-5), mas acabavam por fazer e gostaram.

? As atividades começavam com poucos e terminavam envolvendo todos: "As atividades correm bem, apesar de gostar de ter mais gente a participar" (E1-8, E2-6, LA-11).

? Observadas situações criadas por algumas atividades, por exemplo, maus cheiros das tintas acrílicas e a constatação de alguns idosos terem as mãos pintadas (passou-se a usar luvas): "Bem agora já parece que vão limpas para a mesa" (E13, LA-4)

? Incentivou-se a melhoria dos trabalhos: "Está a ver como está bonito e é capaz". Reforçando com palavras positivas a execução das atividades e desenvolvendo a força de vontade: "Afinal já sou capaz, e que bonito que está" (E1-5, LA-9, LO-3, PR-2 e 7).

? Minimizou-se algumas consequências provocadas por ações não ligadas diretamente ao projeto no seu plano diário de atividades: "Foram às consultas $e$ os idosos gostariam de ter participado nas atividades" (LO-5; PR-4).

? Houve alguns idosos que não estavam a participar diretamente nas atividades que se iam levantando e espreitando o que estava a se fazer. Isto demonstra o interesse que geraram as atividades, convertendo-se numa oportunidade para participarem à nossa pergunta "Então está a gostar do que estamos a fazer?": "Bem eu acho bem, mas tenho medo de não saber fazer!" a qual era orientada se não ficasse bem dava-se um jeito (LO-11).

? A importância em levar para os familiares ou amigos as peças produzidas, fazia que estes os elogiassem nas suas capacidades. Daí promover-se o aumento da participação nas atividades e o entusiasmo na sua realização, por exemplo na confecção de porta-chaves ou pregadeiras: "Enquanto fazíamos as atividades (PR-6) contou com alegria que a sua nora e neto tinham estado lá em casa e que tinham adorado"; "a minha nora gostou muito da pregadeira e disse-me para lhe oferecer uma para colocar naquele casaco verde" (E2-9).

? O gosto das peças produzidas foi enorme: "Estou sempre encantada" (LO-10); "Afinal somos capazes com esta idade" (E2-3); "Este é um dos trabalhos mais bonitos" (E1-7); "Tudo o que fazia achava bonito" (LA-2). 
? Ao longo das atividades os sentimentos iam aflorando melhor e mais rápido, pois disseram "que iam fazer as atividades porque gostavam de se entreterem um pouco' (E1-10, PR-3); o 'tempo assim passa mais depressa" (E1-4). Muitos idosos no fundo gostavam, mas não queriam dizer com medo de parecerem intrometidas: "adoramos fazer as atividades" (LA-5 e 7; LO-2 e 9). Foi importante o reforço positivo estimulado ao longo das sessões e, isso deu-lhes segurança e bem-estar.

?As alegrias e momentos de diversão. Muitas das atividades proporcionaram vários momentos de riso, de alegria, de diversão. Verificaram-se as reações em relação às mãos pintadas com flores, ao amigo que pintou a colega do lado e ela olhou para ele com um ar de zangada, mas segundos depois desataram-se todos a rir, a anedota que foi contada, as máscaras que eram todas diferentes e levou alguns idosos a dizerem: "parece os meus netos, se os meus filhos vissem, não faltariam a dizer, o pai está bom? (LO-4) ou "a mãe hoje deve ter visto um fantasma, não" (E2-5, LA-6).

? Os desejos de quererem participar nas atividades. Antes de irem para o refeitório, os idosos perguntavam quando fariam outras atividades - "no próximo sábado" foi-Ihes informado e retorquiram "tanto tempo, venha antes, amanhã, nós gostamos muito quando cá está" e, assim acumulavam energia para as tarefas seguintes (E2-11; PR-IO,). Chegado a hora de irem para comer o lanche, algumas idosas não "queriam deixar a atividade ao meio" (E2-7).

?As possibilidades de terem experiências novas: "Para onde nos leva?" (LA-8) "Nunca vimos para aqui, desde que estamos cá, nunca vimos" (LA-10), referindose a um local do centro de dia, pois fomos para uma sala ao lado para fazer a atividade de animação física-motora e sensorial (E1-8), já que havia mais espaço e condições.

? A valorização do projeto PIAS, por parte das pessoas que não participaram diretamente nas atividades: "o centro já estava a precisar destes trabalhos' (E111, E2-8; LO-1); 'ficam muito bonitos no móvel e nas paredes, como enfeitam" (LA-1, PR-1),

? O poder do jogo foi muito importante, por exemplo no jogo do galo. Alguns dos idosos disseram: "tem a certeza que conseguimos fazer o jogo?" (E2-1, E1-5, PR- 
2). Insistia-se que era fácil e recapitulava-se os passos: "ficou bonito e afinal é fácil' (LA-9).

? 'As telhas são para o telhado' (E2-10). É verdade, mas vão ver como vão ficar bonitas: 'Bem eu posso pedir á minha filha' (PR-7); 'Não, quem pede sou eu' (LO8). No final estavam contentes e disseram que as filhas não iriam pensar que tinham feito as 'telhas'.

? O segredo da realização das atividades foi 0 fato de haver muito diálogo/comunicação com os idosos, uma alegria e interação nas pequenas coisas que iam desenvolvendo, de tal forma que contagiou às técnicas e os cuidadores. Realçado a importância dos incentivos, estímulos (autoestima) nos idosos e, simultaneamente reforçar a dimensão psicológica-emotiva para melhorar a confiança.

\section{Eficácia valorizada pelos responsáveis e técnicas das instituições}

A análise dos dados das questões feitas aos responsáveis e técnicas dos centros:

*- Cerca de $70 \%$ dos sujeitos das amostras (responsáveis e diretoras técnicas) valorizam 'Muito Bom' o PIAS e o resto de 'Bom' (30\%). Idêntico resultado foi obtido sobre a adequação do PIAS às características dos idosos (70\% disseram 'Muitíssimo adequado' e 30\% de 'Boa adequação'). Estes escores demostram que o PIAS teve a eficácia pretendida.

*- As contribuições dadas pelo PIAS orientaram-se à participação/envolvimento dos idosos, ocupação dos seus tempos livres, no 'sentirem-se bem' no dia-a-dia (satisfação), convivência relacional, originando neles um melhor bem-estar e qualidade de vida.

*- Sobre o impacto do PIAS na qualidade de vida desses idosos, 70\% dos respondentes disseram 'Muitíssimo' e 30\% 'Muito', o que coincide com a alegria e a boa disposição que manifestaram os idosos em todas as sessões.

*- Entre as atividades preferidas pelos idosos, no dizer dos responsáveis e diretoras técnicas dos centros, destacaram maioritariamente os trabalhos manuais e lúdicos (40\%), as atividades físico-motoras (30\%), as culturais (15\%) e cognitivas (15\%). 
*- Sobre a importância da 'animação nos centros de dia', a maioria dos respondentes (70\%) disseram que a assiduidade de atividades, mais diversificadas, considerando-as muito importantes para evitar o tédio, o isolamento e comodismo, de modo a deixarem de pensar nas suas mágoas e tristezas, de ver TV, dormir ou estarem sentados sem mobilidade.

*- Em relação ao contributo das atividades do PIAS nas relações entre os idosos os respondentes destas amostras afirmaram 'Muitíssimo' (70\%) 'Indiferente' (20\%) (casos de centros com muito convívio e fortes relações de amizade - LO e PR) e 'Muito' (10\%).

*- Em relação à aplicação do PIAS os respondentes das amostras dos responsáveis e técnicas disserem 'Muito Bom' (60\%) e os restantes classificaram de 'Boa' (40\%). Por conseguinte, a valorização dos responsáveis e das técnicas foi muito positiva, afirmando alguns deles a grande utilidade da animação gerontológica nos centros de dia e da possibilidade de haver uma animadora ou terapeuta ocupacional em algumas das instituições.

\section{Considerações Finais Algumas Ideias (In) Conclusivas}

Para além das atividades descritas, que constavam no Programa, realizaram-se debates sobre temas locais (história, gastronomia, provérbios, lendas), que assumiram um papel crucial ao longo das sessões, pois os idosos partilharam as suas ideias, foram ouvidos e compreendidos (espaço de expressão livre, onde refletiram e comunicaram sem receios).

Promoveu-se com a aplicação do PIAS que os idosos tivessem mais oportunidades de refletirem sobre temáticas do seu quotidiano, participando nas tarefas, atividades e jogos didáticos. O seu envolvimento permitiu aumentar a sua autoestima, o nível de autoconfiança e motivação. Os coletivos de idosos, em cada centro, ficaram mais sólidos, unidos e com maior dinamismo. Criado um ambiente mais dinâmico em que os idosos se sentiram atores e protagonistas do que fizeram, desenvolvendo a parte comunicativa e criativa. A entre ajuda, a colaboração, a preocupação em concretizar os objetivos da tarefa, enquanto grupo, também foi um dos aspetos destacáveis. Em termos globais, as atividades assumiram-se como promotoras de dinamismo, interação, participação e convivência (OLIVEIRA, 2008).

A eficácia e a valorização do PIAS nas instituições sintetizam-se nos seguintes pontos: 
*- O que os idosos fizeram ('Possibilidades de Ser'). Os idosos utilizaram nas atividades a base de materiais reciclados e reutilizados, de forma a rentabilizar os recursos e/ou custos (educação ambiental e ecológica). Há medida que os trabalhos iam sendo feitos o grau de exigência foi aumentando, gerando nos idosos o prazer de executar e fazer, ficando mais orgulhosos (autoestima), sentiam-se bem e felizes, satisfeitos, alegres e mais confortáveis interiormente ('Eu'). Incutiu-se-lhes a liberdade de fazerem e escolherem o que queriam realizar, tendo sido gratificante vê-los a tomar decisões, manifestarem reações e atitudes interessantes. Os incentivos foram importantes, pois os idosos sentiramse mais confiantes e seguros nas suas capacidades de 'fazer'.

*- Ambiente institucional (Relação dos idosos: empatia, amizade, convívio e afetividade). O PIAS desenvolveu boas relações inter/intra nos idosos, havendo sempre alguns, que no início ao terem pouca confiança, sentiam-se inseguros. Com o passar do tempo ganharam confiança, perderam o temor e insegurança em si e conseguiram partilhar e participar ativamente em atividades. Daí a satisfação pessoal e social manifestada pelos idosos, responsáveis e técnicas (eficácia do PIAS).

*- Aceitação pelos responsáveis/técnicos das instituições da animação gerontológica. Em geral os responsáveis, as técnicas e funcionários mostraram-se muito satisfeitos com as atividades de animação sociocultural, participando e dando apoios (material, espaços), de modo a termos as atividades organizadas, valorizando positivamente o PIAS.

*- Programa de intervenção (PIAS). A sua aplicação foi bem aceite pelos idosos, pelos responsáveis e técnicas. Após a sua execução refletiu-se sobre a possibilidade do programa poder ser alterado, incluindo outras atividades (musicoterapia, ateliê de tecnologias). Os idosos ficaram com uma boa imagem do que é a animação sociocultural, de tal modo que exigiam a presença de animadoras ou terapeutas ocupacionais nos seus centros. O Programa fê-los sentir-se mais úteis e felizes, influenciando-os positivamente ao nível físico, psíquico/emocional e, consecutivamente, o aumento do sentido de confiança e de felicidade (SCHAIE; WILLIS, 2003; ZIMERMAN, 2005).

Na verdade, o estudo e a aplicação eficaz do PIAS demonstraram o contributo da animação na satisfação com a vida e na qualidade de vida dos idosos de centros de dia 
(JACOB, 2007). As relações sociais, as redes de relações (convivência), as atividades de animação sociocultural, e o apoio social são aspetos fulcrais, especialmente no que diz respeito às contribuições dadas aos idosos para terem um bem-estar e uma satisfação com a vida no seu envelhecer (CARDÃO, 2009).

Em definitivo, o objetivo do envelhecimento ativo é o de proporcionar uma maior integração (cidadania ativa e participativa) e uma motivação para a vida das populações mais idosas, assente em medidas/serviços de políticas sociais destinados à prevenção, intervenção e inclusão. Pensou-se que nessa concretização de medidas os cuidadores formais/informais (voluntariado) e os técnicos são fundamentais à satisfação e qualidade de vida (MARQUES, 2011). A aproximação profissional a essas pessoas no envelhecimento implica um atuar/agir, a partir das necessidades e da perceção do idoso como sujeito (ator e protagonista das ações e intervenções) e não como alguém dependente que não sabe dialogar e atuar por si mesmo. O segredo de uma velhice bem-sucedida depende da capacidade psicológica de cada um, em encontrar o seu caminho de envelhecimento exitoso, caminho esse que cedo se inicia, com progressivas perdas, dependendo do diálogo entre o sistema biológico, psicológico e social do indivíduo e das repercussões que têm entre si (PAÚL; FONSECA, 2005).

\section{Referências}

ARAÚJO, L .F.; CARVALHO, Van L. Velhices: estudo comparativo das representações sociais entre idosos de grupos de convivência. Textos Envelhecimento, Rio de Janeiro, v.7, n. 1, p. 10-22, 2004.

CARDÃO, S. O idoso Institucionalizado. Lisboa: Coisas de Ler, 2009.

ERIKSON, E. El ciclo de la vida completado. Barcelona: Paidós, SET \& SET, 2000.

GONZÁLEZ RODRÍGUEZ, B.; MUÑOZ MARRÓN, E. Estimulación de la memoria en personas mayores. Madrid: Síntesis, 2008.

JACOB, L. Animação de Idosos: Atividades. 2. ed. Porto: Editora Ambar, 2007.

MARQUES, A. A animação cultural com idosos e o processo de individuação. Revista Práticas de Animação, Madeira, v. 5, n. 4, p.1-9, out. 2011.

NAZARETH, J. M. Crescer e envelhecer: constrangimentos e oportunidades do envelhecimento demográfico. Lisboa: Editorial Presença, 2009.

OLIVEIRA, J. Psicologia do idoso. Porto: Livpsic, 2008.

PAÚL, C. M.; FONSECA, A.M. Envelhecer em Portugal. Lisboa: Climepsi, 2005. 
PÉREZ BLASCO, J. Aprendiendo de los grandes cambios vitales. Valencia: Publ. Universitat de Valence, 2013.

QUARESMA; M. O sentido das idades da vida, interrogar a solidão e a independência. Lisboa: CESDET - I.S.S.S., 2004.

SCHAIE, K.W.; WILLIS, S.L. Psicología de la edad adulta y la vejez. Madrid: Pearson, 2003.

SILVA, E.; MOINHOS, R. Animação sociocultural: módulos opcionais. Lisboa: Plátano Editora, 2010.

ZIMERMAN, G.I. Velhice: aspetos Biopsicossociais. Porto Alegre: Artmed Editora, 2005. 2005. 
Recebido em: 21/03/2017

Aceito em: 15/12/2017 